\title{
Morphological and Morphometric Study of the Clavicle: A Tool for Gender Identification in Cadavers
}

\author{
Bárbara Guedes de Almeida, ${ }^{1}$ Maria Luana Barbosa de Sousa, ${ }^{2}$ Heitor Victor Veiga da Costa, ${ }^{3}$ Carolina Peixoto Magalhães, ${ }^{4}$ \\ Jaciel Benedito de Oliveira, ${ }^{5}$ Renata Cristinny de Farias Campina ${ }^{5}$
}

${ }^{1}$ Federal University of Pernambuco (UFPE) Nursing Program Student

${ }^{2}$ Federal University of Pernambuco (UFPE) Odontology Program Student

${ }^{3}$ Federal University of Pernambuco (UFPE) Statistic Program Student

${ }^{4}$ UFPE Vitória Academic Center (CAV/UFPE) Professor of Anatomy

${ }^{5}$ UFPE Anatomy Department Professor

Disclose and conflicts of interest: none to be declared by all authors

\begin{abstract}
Introduction: when we relate anatomical characteristics of the human skeleton with the determination of the individual's biological profile, we commonly study the bony segments of the head and pelvis. However, in many forensic cases, these two segments are either not found or damaged, making it necessary to know and study other bony parts. The human clavicle is considered relatively resistant to taphonomic factors, being of extreme importance when it comes to archeology and forensic science. The present research aims to assist forensic professionals, anthropologists, and anatomists in the identification of individuals through analysis of the morphometric dimensions of clavicles, verifying their reliability as a tool to gender identification, as well as providing additional data for the possible construction of tables that correspond to the ethnicities of the Brazilian population. To reach the proposed objective, we used 102 pairs of clavicles, among which 37 pairs were of female and 65 of male subjects, all originated from the Human Bone Collection of the anatomy laboratory of Universidade Federal de Pernambuco. Six measurements were performed: maximum length, circumference of the diaphysis, height and width of acromial end, and height and width of sternal end. A morphological measurement called impression for costoclavicular ligament, also known as rhomboid fossa, was also observed.
\end{abstract}

Keywords: Bones; Forensic anthropology; Anatomy; Legal medicine.

\section{Introduction}

The knowledge of anthropology is important in the process of skeletal identification because it is a common situation to find skeletons missing a few bones, which makes it difficult to identify the gender, age, race or anything that may characterize that individual. ${ }^{1}$ Still in the scope of forensic anthropology, the physical identification of an individual includes specific procedures that follow rigorous methodologies based on scientific research. ${ }^{2}$

One of the methodologies used for biotipological identifi- cation is related to the socalled forensic osteology, a branch of forensic anthropology. ${ }^{3}$ Through the morphoscopic and morphometric analyses of some bones, we can determine an individual's gender, ancestry, age, and biotype. ${ }^{4}$

The human clavicle is considered relatively resistant to taphonomic factors,${ }^{5,6}$ being of extreme importance when it comes to archeology and forensic science. ${ }^{6}$ In general, the clavicles of female individuals are shorter, thinner, and less curved, while those of male individuals are longer, more curved and more robust. ${ }^{7}$ In women, the rhomboid fossa (also called impression for costoclavicular ligament [ICL]) is absent in 97.1\% of the cases, but, in male subjects, it is absent in only $36.4 \%$ of the cases. The rhomboid fossa is more often present in the right clavicle, and it is an important anatomical accident for gender determination. ${ }^{8}$

In previous studies, the clavicles presented the rhomboid fossa of the depressive type more frequently in men, with $60.76 \%$ of them being on right side and $27.5 \%$ on the left side. In female subjects, the data show a rate of $6.81 \%$ on both sides. The rhomboid fossa of the smooth and flat type was more present in the clavicles, of female subjects, with a rate of $20.45 \%$ on the left side and $31.81 \%$ on the right side. The soft type was found in $18.18 \%$ of the left-side clavicles and $13.63 \%$ in the right-side ones. ${ }^{7}$ In other studies, it was observed that there is a relation between the presence of the rhomboid fossa and the gender of the individual, showing a greater incidence of this fossa in men. ${ }^{8-18}$

In previous studies, it was observed that besides the circumference of the diaphysis (CD), another important measure to consider in the clavicle was the average super-inferior diameter. ${ }^{11}$ The maximum length (ML) was also evaluated with a sample of 98 male clavicles, having a mean of $158.24 \mathrm{~mm}$ in length, and a sample of 100 female clavicles having a mean of $140.28 \mathrm{~mm}$, 
concluding that the male clavicles are longer. ${ }^{2}$

Resistant to taphonomic processes, the human clavicle becomes a preserved bone segment in the medical-legal or bioanalytical field. ${ }^{6}$ In this way, the use of the clavicle is of high relevance to determinate sexual dimorphism in cases in which the bones that would facilitate this information is not available. In fact, many studies have addressed the sexual dimorphism across the clavicle in various world populations. ${ }^{12-14}$ However, there are still few studies involving the Brazilian population. So, the present study aims to assist forensic researches, anthropologists and anatomists in the identification of individuals through analysis of the morpho-metric dimensions of the clavicle, verifying their reliability as a tool for sexual diagnosis, as well as providing additional data for the possible construction of tables that correspond to the ethnicities of the Brazilian population.

\section{Materials and Methods}

One-hundred and two pairs of clavicles were used, 37 of which were of female subjects and 65 that belonged to male subjects. All clavicles used in the present study came from the collection of human bones of the anatomy laboratory of Universidade Federal de Pernambuco, in the state of PE, Brazil. Despite the fact that the gender was known, the researchers only had access to the information after the measurements were completed. Those bones whose varia-bles could not be measured by the presence of structural variations derived from bone pathologies (for example: osteophytes, fractures, porosity with bone wear) were removed from the sample.

Six measurements were performed: ML, CD, height and width of acromial end (HAE and WAE), height and width of the sternal end (HSE and WSE). In addition, the ICL (also known as rhomboid fossa) was also observed(Table 1)(Fig. 1).
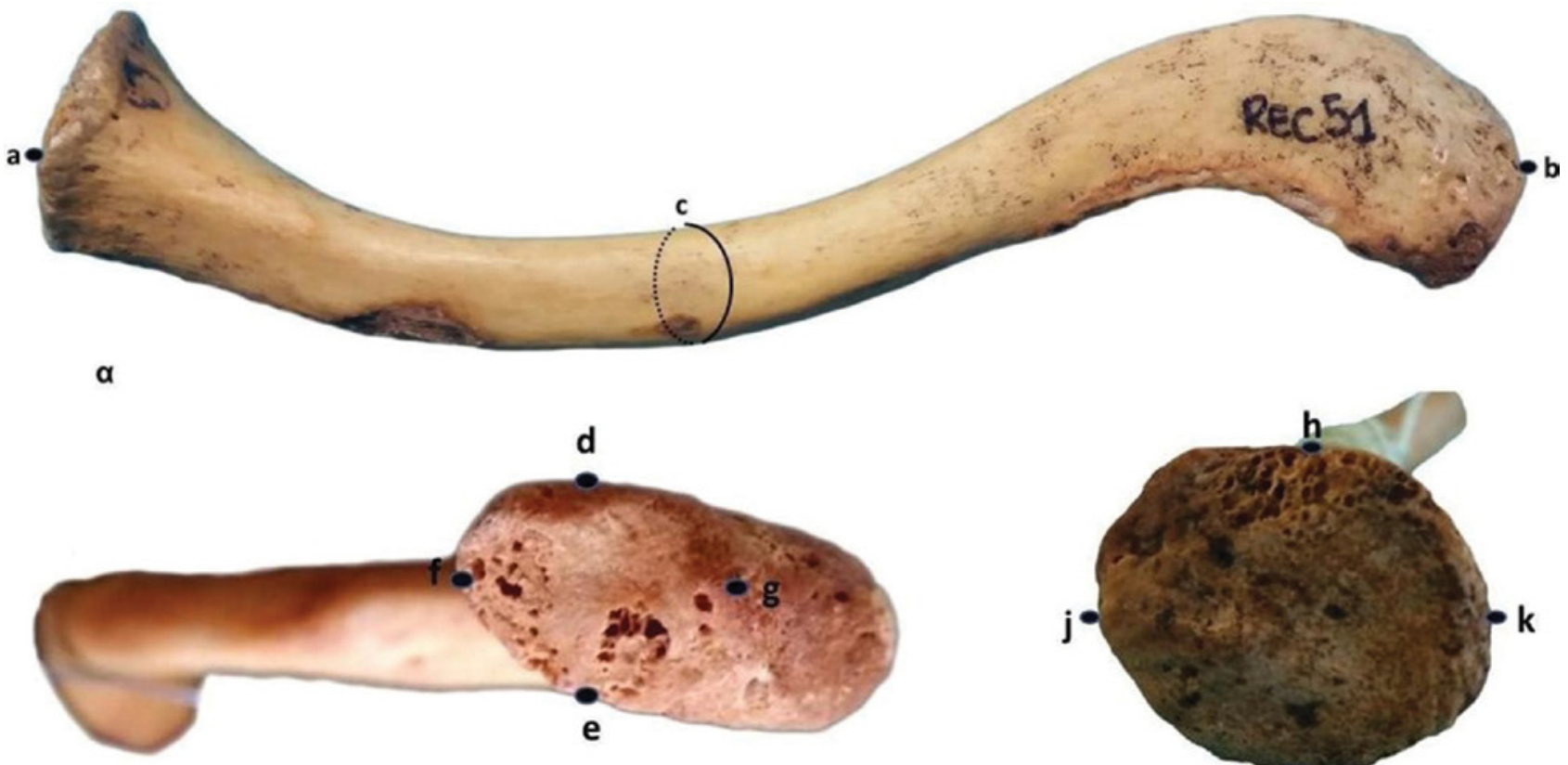

B

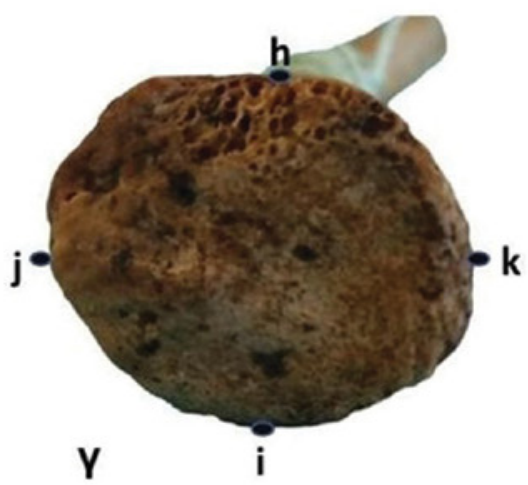

Figure 1. Clavicle upper view $(\alpha)$; Acromial end view ( $\beta$ ); Sternal end view (y). Subtitles: $M L$, maximum length: ab, CD, circumference of diaphysis: $c$; HAE, height of acromial end): de; WAE, width of acromial end: fg; HSE, height of sternal end hi; WSE, width of sternal end): jk.

Table 1. Description of clavicle measurements

\begin{tabular}{l|c|l|c}
\hline \multicolumn{1}{c|}{ Measurements } & Initials & \multicolumn{1}{c}{ Descriptions } & References \\
\hline Maximum length & ML & Length between acromial and sternal end & 2,17 \\
\hline Circumference of diaphysis & CD & Circumference of the middle of the clavicle & 2,14 \\
\hline Height of the acromial end & HAE & Measurement between the top and bottom of the acromial end & 18 \\
\hline Width of the acromial end & WAE & Measurement between the left and right limits of the acromial end & 14,27 \\
\hline Height of the sternal end & HSE & Measure between the lower and upper part of the sternal end & 14,27 \\
\hline $\begin{array}{l}\text { Width of the sternal end } \\
\text { Impression for costoclavicular } \\
\text { ligament }\end{array}$ & WSE & Measurement between the left and right limits of the sternal end & $\begin{array}{l}\text { Qualitative measurement based on depression or elevation in } \\
\text { costoclavicular ligament impression }\end{array}$ \\
\hline
\end{tabular}

Abbreviations: CD, circumference of diaphysis; HAE, height of acromial end; ML, maximum length; SD, standard deviation; WAE, width of the acromial end; WSE, width of the sternal end. 
In addition to morphometric measures, a mathematical method is used in the literature, in which some measures of the clavicle are applied in a formula to find the robustness index (RI)19 (formula below) expressed in \%. This index represents the relationship between the circumference of the diaphysis and the ML and expresses the robustness of the clavicle. ${ }^{14}$ According to Kralik et al (2014), this measure become effective only on the righ-side clavicles of female subjects when they are aged 46 to 70 years or over 70 years. ${ }^{14}$

$$
\mathrm{SDI}=\frac{\text { mean }(\text { male })-\text { mean (female }) \times 100}{\text { mean }(\text { male })}
$$

In addition, we used the sexual dimorphism index (SDI) to express (in \%) the gender differences using the averages of the aforementioned measures. ${ }^{14,20-23}$ According to Frayer, ${ }^{24}$ we consider a strong sexual dimorphism when a certain measure has a SDI greater than $10 \%$.

$$
\mathrm{RI}=\frac{\text { circumference of the diaphysis }}{\text { maximum length of clavicle }} \times 100
$$

The materials used for such measurements were: 3,200 gr precision balance (Ramuza) with $0.01 \mathrm{~g}$ division, $150 \mathrm{~mm}$ digital caliper (Brasfort), flexible barbell wire and $30 \mathrm{~cm}$ magnetic ruler (Tec) graduated every $1 \mathrm{~mm}$. To identify differences between the variables according to the gender of the individual, the Mann-Whitney test was applied. To identify differences between the sides, for the subjects with the same gender, the Wilcoxon-Mann-Whitney test was computed due to the correlation existent in the process. For the variable ICL, for being categorical, the evaluation was done using Pearson Chi-squared test for independence. For the calculations, the statistical programming language $\mathrm{R}$ ( $\mathrm{R}$ core team) version 3.5.4 was used. The normality test used was the ShapiroWilk test. Provided that all data did not show a normal distribution, non-parametric tests were used.

\section{Ethics}

The ethics committee of CCS/UFPE, CAAE 66287517. 7.0000.5208, previously authorized all procedures and meas-urements performed in the present bone collection.

\section{Results and Discussions}

When we analyzed the RI,19 we found $25.94 \%$ (right) and $25.62 \%$ (left) for the clavicles of male subjects, whereas the clavicles of female subjects presented RI of $24.79 \%$ (right) and $25.10 \%$ (left). These data corroborated with studies by Kralik et al, which showed a significant increase in the Men's robustness index than in the women's, in the collections of human skeletons from the University of Athens. Other studies analyzed the RI of each antimerism between men and women and found the indices of $26.47 \%$ (right) and $25.73 \%$ (left) in men in relation to the indices of $24.32 \%$ (right) and $23.89 \%$ (left) in women. ${ }^{12,14}$

The highest SDI score was weight, with $40.37 \%$ in the right clavicle and $45.06 \%$ in the left. In addition, we observed that after the weight we had the $\mathrm{CD}$, with rates of $12.65 \%$ on the right and $14.56 \%$ on the left side. Then, the ML, with $11.57 \%$ on the right and $13.24 \%$ on the left side. Soon after, we have the WSE, with $13.14 \%$ in the right and $11.04 \%$ in the left side. The WAE was observed, with $10.41 \%$ on the right and $11.00 \%$ on the left side. At the HAE, we observed a discrepancy regarding the values obtained between the right and left clavicles, which were $5.01 \%$ and $14.08 \%$, respectively. At the height of sternal end, we obtained the values of $4.32 \%$ on the right and $4.94 \%$ on the left side (Table 2 ). Corroborating with our results, in studies evaluating the SDI, Fernandes ${ }^{25}$ found measurements of the circumference of the diaphysis of $12.60 \%$. On the other hand, the SDI of the ML was < 10\%, precisely $7.92 \%$. From older to more recent studies, there is agreement that the clavicle diameter as well as the length of the clavicle have shown satisfactory results in gender estimation. ${ }^{10,13,26}$

There were statistically significant differences

Table 2. Sexual dimorphism index expressed as a percentage of each variable of the left and right clavicle and its mean, respectively

\begin{tabular}{l|c|c|c}
\hline Variables & Right clavicle & Variables & Right clavicle \\
\hline ML & 11.57 & 13.24 & 12.40 \\
\hline CD & 12.65 & 14.56 & 13.60 \\
\hline WEIGHT & 40.37 & 45.06 & 42.71 \\
\hline HAE & 5.01 & 14.08 & 9.54 \\
\hline WAE & 10.41 & 11.00 & 10.70 \\
\hline HSE & 4.32 & 4.94 & 4.63 \\
\hline WSE & 13.14 & 11.04 & 12.09
\end{tabular}

Abbreviations: Abbreviations: $\mathrm{CD}$, circumference of diaphysis; $\mathrm{HAE}$, height of acromial end; ML, maximum length; SD, standard deviation; WAE, width of the acromial end; WSE, width of the sternal end.

between the genders regardless of the antimerism, among the ML, CD, weight, HAE, WAE, and WSE measurements, all with $p<0.01$ (Table 3 ). Corroborating with our studies, Papaioannou et al ${ }^{27}$ developed a research about the morphometry of the clavicle and observed that, regardless of the antimerism, the ML of the clavicle was higher in males (ML - 152.2) than in females (ML - 133.3). Furthermore, another recent study with the South African population showed that the male subjects had larger clavicles than the female subjects (ML male: $154.45 \pm 11.68$; ML female: 139.76 $\pm 9.84) .{ }^{28}$ However, it is interesting to note that several studies have shown that the male clavicles are more horizontally curved in relation to female clavicles. ${ }^{29-31}$

As for the analysis between the genders, tests were done for each antimerism. For the bones on the right side, significant differences were found between the variables clavicle diaphysis circumference $(p<0.01)$, ML $(p<0.01)$, weight $(p<0.01)$, HAE $(p<0.01)$, WAE $(p$ 
- 0.028) and for WSE $(p<0.01)$. For left antimere, the results were similar, with $p<0.01$ in the measurements above, except for the WAE, in which the $p$-value was 0.034 (Table 4). Several studies confirm that the total length of the clavicle is greater in men than in women. . $^{14,17,32}$

To analyze the qualitative variable ICL, we noticed that none of the sides were associated with the type

Table 3. Statistical description and results of clavicle measurements

\begin{tabular}{|l|l|l|c}
\hline \multicolumn{1}{c|}{ Variables } & \multicolumn{1}{c|}{$\begin{array}{c}\text { Male } \\
\text { mean } \pm \text { SD }\end{array}$} & $\begin{array}{c}\text { Female } \\
\text { mean } \pm \text { SD }\end{array}$ & \multicolumn{1}{c}{$\boldsymbol{P}^{*}$} \\
\hline ML & $152.2 \pm 9.41$ & $133.3 \pm 8.13$ & $<0.01$ \\
\hline CD & $39.1 \pm 3.70$ & $3.38 \pm 4.26$ & $<0.01$ \\
\hline WEIGHT & $20.5 \pm 5.16$ & $11.8 \pm 3.44$ & $<0.01$ \\
\hline HAE & $11.9 \pm 2.43$ & $10.8 \pm 2.44$ & $<0.01$ \\
\hline WAE & $20.4 \pm 4.60$ & $18.3 \pm 4.18$ & $<0.01$ \\
\hline WSE & $22.9 \pm 3.95$ & $20.1 \pm 3.18$ & $<0.01$ \\
\hline
\end{tabular}

Abbreviations: $C D$, circumference of diaphysis; $\mathrm{HAE}$, height of acromial end; $\mathrm{ML}$, maximum length; SD, standard deviation; WAE, width of the acromial end; WSE, width of the sternal end.

*Indicates significance for the Mann-Whitney test. of gender, in which the statistical tests had values of $p-0.3334$ (for the left side) and 0.259 (for the right side). These data corroborate with those found by Jit et $a l,{ }^{33}$ whose results did not find statistical differences between gender and the incidence of the rhomboid fossa in Indian individuals. ${ }^{33}$ The results can be found in Table 5.

Analyzing the predictive models based on the methodology of Hothorn et $a l,,^{34,35}$ it is shown that when using the right antimere bones, when the ML is shorter than or equal to 136.33, the model tends to classify the bones as female and for values above 136.33 as male (Fig. 2). The results are similar for the left side; however, the value of the ML to be compared in this case is 145.02; that is, any value below 145.02 will be classified as female and above this value we will classify them as male (Fig. 3).

Regarding the best antimere studies to be analyzed in morphological and morphometric studies, we observed in Table 1 the predictive performance of each model, and the one that works best is the bone that uses the right side, which has an accuracy of $94.4 \%$ (Table 6).

Table 4. Statistical description and results of clavicle measurements using the t-test

\begin{tabular}{|c|c|c|c|c|c|c|c|c|}
\hline \multirow[t]{2}{*}{ Measures } & \multirow[t]{2}{*}{ Side } & \multicolumn{3}{|c|}{ Male } & \multicolumn{3}{|c|}{ Female } & \multirow[b]{2}{*}{$p$} \\
\hline & & $\mathbf{N}$ & Mean & SD & $\mathbf{N}$ & Mean & SD & \\
\hline \multirow{2}{*}{$M L \S, £$} & Right & 56 & 150.5 & 9.33 & 34 & 133.1 & 8.89 & 0.01 \\
\hline & Left & 57 & 153.8 & 9.29 & 32 & 133.4 & 7.38 & 0.01 \\
\hline \multirow{2}{*}{$C D$} & Right & 56 & 39.0 & 3.96 & 34 & 34.0 & 4.75 & 0.01 \\
\hline & Left & 59 & 39.3 & 3.48 & 32 & 33.5 & 3.73 & 0.01 \\
\hline \multirow{2}{*}{ Weight ${ }^{\mathrm{f}}$} & Right & 58 & 20.5 & 5.40 & 37 & 12.2 & 3.57 & 0.01 \\
\hline & Left & 61 & 20.5 & 4.97 & 34 & 10.1 & 2.03 & 0.01 \\
\hline \multirow{2}{*}{$\mathrm{HAE}^{\mathrm{f}}$} & Right & 56 & 12.0 & 2.54 & 34 & 11.4 & 2.67 & 0.01 \\
\hline & Left & 58 & 11.9 & 2.34 & 32 & 10.1 & 2.03 & 0.01 \\
\hline \multirow{2}{*}{ WAE } & Right & 55 & 20.5 & 4.38 & 31 & 18.4 & 4.05 & 0.028 \\
\hline & Left & 59 & 20.4 & 4.84 & 27 & 18.1 & 4.39 & 0.034 \\
\hline \multirow{2}{*}{ WSE } & Right & 56 & 23.2 & 3.65 & 35 & 20.2 & 3.39 & 0.01 \\
\hline & Left & 57 & 22.5 & $4>23$ & 32 & 20.1 & 2.98 & 0.01 \\
\hline
\end{tabular}

Abbreviations: CD, circumference of diaphysis; HAE, height of acromial end; ML, maximum length; SD, standard deviation; WAE, width of the acromial end; WSE, width of the sternal end.

Indicates significance for the Mann-Whitney test.

§Indicates significance for the Wilcoxon-Mann-Whitney test for males.

Elndicates significance for the Wilcoxon-Mann-Whitney test for the female.

Table 5. Qualitative analysis of the rhomboid fossa or impression for costoclavicular ligament

\begin{tabular}{|c|c|c|c|c|c|c|}
\hline \multirow{3}{*}{ Impression for costoclavicular ligament } & \multicolumn{2}{|c|}{ Left sides } & & Right sides & & \\
\hline & \multicolumn{2}{|c|}{ Gender } & & Gender & & \\
\hline & Male & Female & X2 (p-value) & Male & Female & X2 (p-value) \\
\hline Elevation & 19 & 14 & 2.196 & 20 & 16 & 2.702 \\
\hline Depression & 27 & 10 & $(0.333)$ & 32 & 12 & $(0.259)$ \\
\hline Nothing & 11 & 4 & & 5 & 2 & \\
\hline
\end{tabular}




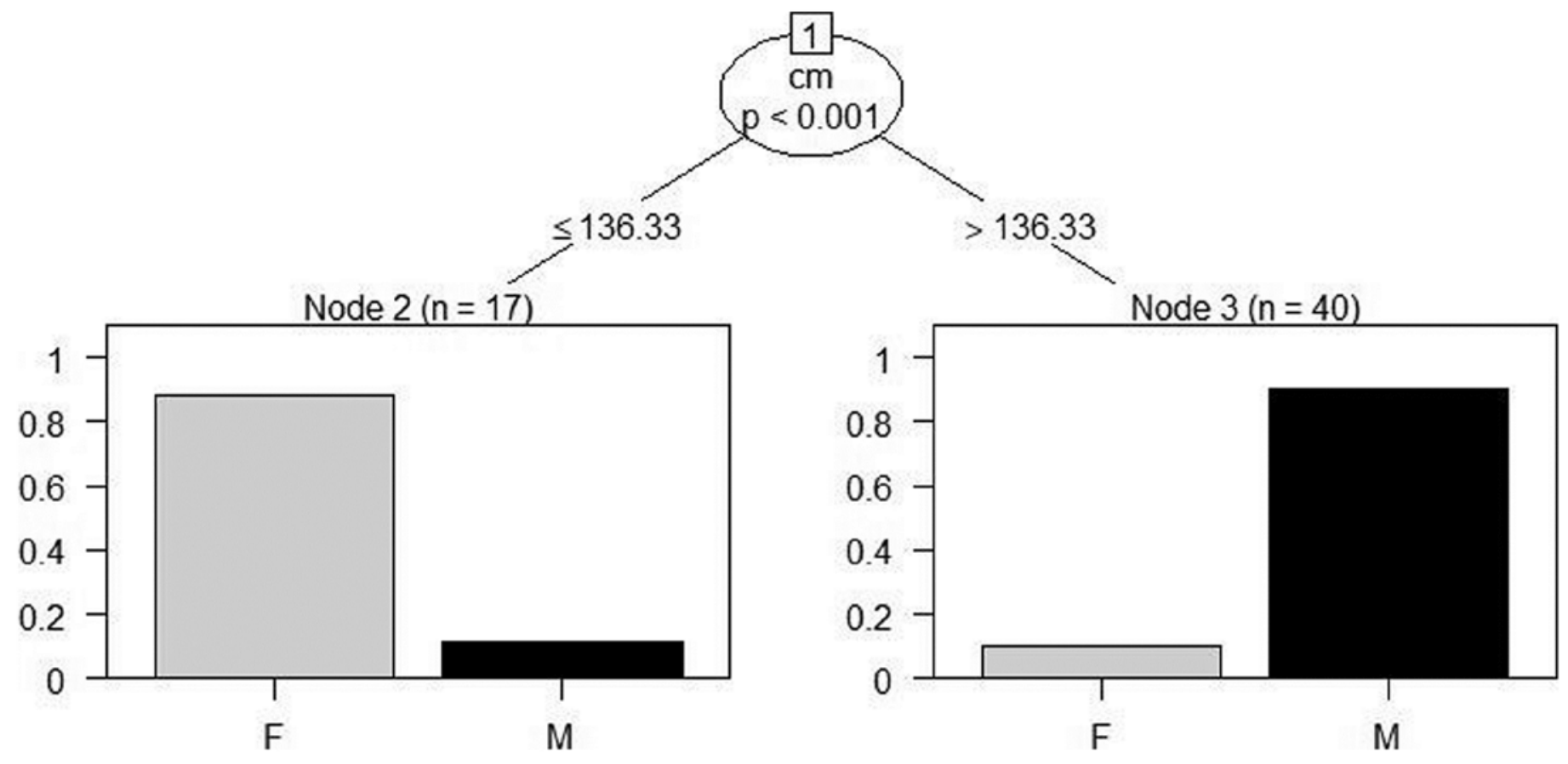

Figure 2. Predictive models for right-side bones.

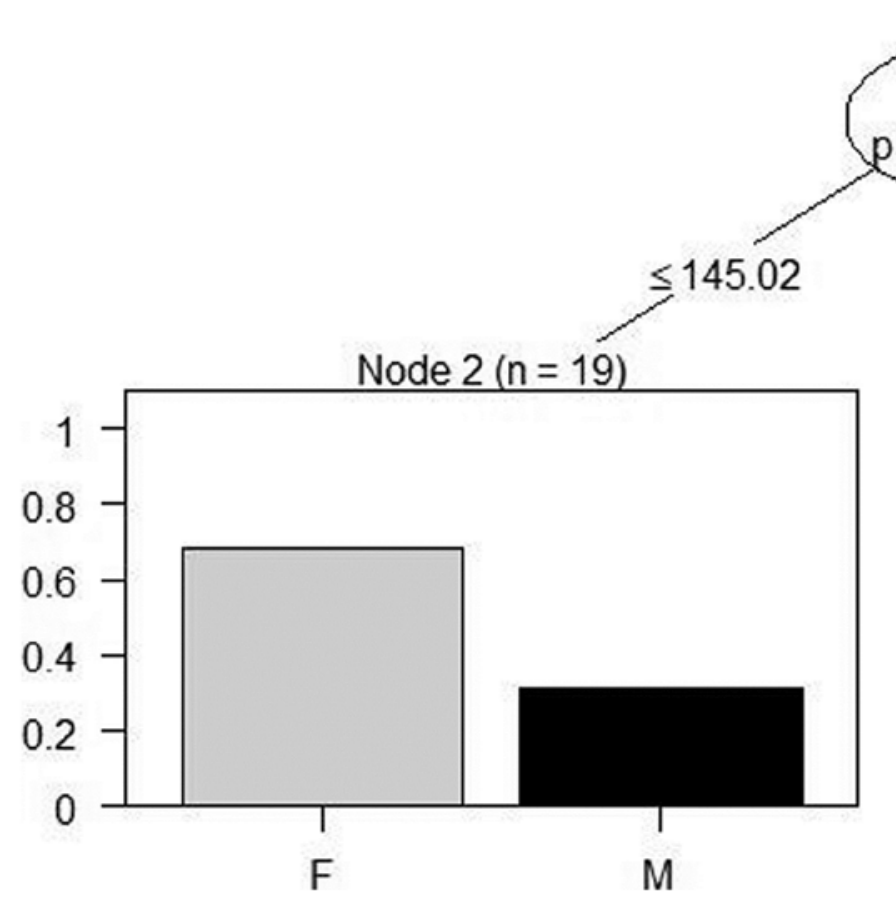

Figure 2. Predictive models for right-side bones.

Table 6. Predictive performance of statistical models

\begin{tabular}{l|l|l|l|l}
\hline \multirow{2}{*}{} & \multicolumn{2}{|c|}{ Right side } & \multicolumn{2}{c}{ Left side } \\
\cline { 2 - 5 } & Estimated & & Estimated & \\
\hline Observed & $\mathrm{F}$ & $\mathrm{M}$ & $\mathrm{F}$ & $\mathrm{M}$ \\
\hline $\mathrm{F}$ & $16.7 \%$ & $5.6 \%$ & $47.4 \%$ & $0.0 \%$ \\
\hline $\mathrm{M}$ & $0.0 \%$ & $77.8 \%$ & $10.5 \%$ & $42.1 \%$ \\
\hline
\end{tabular}

\section{Conclusions}

Gender estimation is one of the first steps in determining unidentified remains. Over the years, studies have always indicated that the best bone segments for such study are the skull and pelvis. However, the study of the clavicle has shown that it may be an alternative bone element for the gender identification in the absence of other important bones, 
such as the skull and pelvis, thus contributing to the study of anthropology and forensic medicine. In the present study, the ML of the clavicle was one of the measures that showed the greatest significance; this shows that the male clavicle, due to the more pronounced muscular insertions, exhibits a larger and more robust anatomical aspect to the detriment of the female clavicle. We observed that most of the measure-ments showed a significant degree of sexual dimorphism above 10\%. Although all the measures evaluated were larger in males, only the ML of the clavicle could be analyzed for the predictive models of
Hothorn et al, in which it was demon-strated that the right antimeric presented a better accuracy of $94.4 \%$ for the studies concerning the morphometry of the clavicle.

\section{Acknowledgments}

The authors are grateful for the partnership between the Federal University of Pernambuco (UFPE) and the Foundation for the Support of Science and Technology of the State of Pernambuco (FACEPE), which through the Academic Incentive Grant Program contributed to the financial support of this study.

\section{References}

1. Silva RFd, Nunes FG, Neto JCdF, Rege ICC, Júnior ED. Forensic importance of panoramic radiographs for human identification. Rev Gaucha Odontol 2012;60(04):527-531.

2. Bass WM. Human Osteology: A laboratory and field manual. 5th edition. 2005.

3. White TD, Folkens PA. The human bone manual. Elsevier academic press; 2005.

4. Bass WM. Human Osteology: A Laboratory and Field Manual. Society MA, editor 1995.

5. Akhlaghi $M$, Moradi B, Hajibeygi $M$. Sex determination using anthropometric dimensions of the clavicle in Iranian population. J Forensic Leg Med 2012;19(07):381-385.

6. Black S, Scheuer L. Age changes in the clavicle: from the early neonatal period to skeletal maturity. Int J Osteoarchaeol 1996; 6:425-434.

7. Bhat S, Asif M, Manjegowda DS, Radhakrishna S, Shivarama. Rhomboid fossa and mid shaft circumference of the clavicle - anthropological study in North Karnataka population. Nitte University Journal of Health Science 2015;5(03):

8. Prado FB, de Mello Santos LS, Caria PH, et al. Incidence of clavicular rhomboid fossa (impression for costoclavicular ligament)in the Brazilian population: forensic application. J Forensic Odontosto matol 2009;27(01):12-16.

9. Cave AJ. The nature and morphology of the costoclavicular ligament. J Anat 1961;95:170-179.

10. Parsons FG. On the Proportions and Characteristics of the Modern English Clavicle. J Anat 1916;51(Pt 1):71-93.

11. Fernandes JRdSG. Diagnose Sexual através da Clavícula numa amostra da Coleção de Esqueletos Identificados do século XXI. Porto: Universidade do Porto; 2015.

12. McCormick WF, Stewart JH, Greene H. Sexing of human clavicles using length and circumference measurements. Am J Forensic Med Pathol 1991;12(02):175-181.

13. Frutos LR. Determination of sex from the clavicle and scapula in a Guatemalan contemporary rural indigenous population. Am J Forensic Med Pathol 2002;23(03):284-288.

14. Králík M, Urbanová P, Wagenknechtová M. Sex assessment using clavicle measurements: inter- and intra-population comparisons. Forensic Sci Int 2014;234:181.e1-181.e15.

15. Paiva LAS, Rabelo APA. Identificação humana com a utilização de prótese total superior e de técnica de sobreposição de imagens. Saúde, Ética \& Justiça. 2010;15(01):40-45.

16. Franklin D, O'Higgins P, Oxnard CE, Dadour I. determination of sex in south african blacks by discriminant function analysis of mandibular linear dimensions : A preliminary investigation using the zulu local population. Forensic Sci Med Pathol 2006;2(04): 263268.

17. Yang JC, Lin KJ, Wei HW, Tsai CL, Lin KP, Lee PY. Morphometric Analysis of the Clavicles in Chinese Population. BioMed Res Int 2017;2017:8149109.
18. Martin R, Saller K. Lehrbuch der Anthropologie, in systematischer Darstellung. Stuttgart; 1957.

19. Silva JTdSdOe. Antropologia Forense e Identificação Humana. Porto: Universidade Fernando Pessoa; 2015.

20. Jit I, Singh S. The sexing of the adult clavicles. Indian J Med Res 1966;54(06):551-571

21. Charisi D, Eliopoulos C, Vanna V, Koilias CG, Manolis SK. Sexual dimorphism of the arm bones in a modern greek population. J Forensic Sci 2011;56(01):10-18

22. Bresson F, Crubézy E. Apport de Chasséens de Saint- Paul TroisChateaux (Drôme) au Problème de la Gracilisation. Résultants Méridionales de Préhistoire RéceneValença1994.

23. Morphé WR. Análise das proporções entre os membros, dimorfismo sexual e estatura de uma amostra da coleção de esqueletos identificados do museu antropológico da Universidade de Coimbra. Coimbra: Universidade de Coimbra; 2000.

25. Frayer D. Sexual dimorphism and cultural evolution in the late Pleistocene and Holocene of Europe. J Hum Evol 1980; 9:399-416. 25. Fernandes JRdSG. Diagnose Sexual através da Clavícula numa amostra da Coleção de Esqueletos Identificados do século XXI. Coimbra: Universidade de Coimbra; 2015.

26. Steel FL. Further observations on the osteometric discriminant function. The human clavicle. Am J Phys Anthropol 1966;25(03): 319322.

27. Papaioannou VA, Kranioti EF, Joveneaux P, Nathena D, Michalodimitrakis $M$. Sexual dimorphism of the scapula and the clavicle in a contemporary Greek population: applications in forensic identification. Forensic Sci Int 2012 Apr 10;217(1-3):231 e1-7.

28. Shelby S, Tanya RP, Mandi A. The influence of biological affinity and sex oh morphometric parameters of the clavicle in a South African sample. Am J Hum Biol 2018;30(05):

29. Olivier G. Anhthropologique de la clavicule III - la clavicule du Français. Paris1951.

30. Kaur H. Harjeet, Sahni D, Jit I. Length and curves of the clavicle in Northwest Indians. J Anat Soc India 2002;51:199-209.

31. Bilodi AKS, Sinha BN, Kumaran S. Some observation on human clavicle. JNMA J Nepal Med Assoc 2002;41:441-445.

32. Papaioannou VA, Kranioti EF, Joveneaux P, Nathena D, Michalodimitrakis $M$. Sexual dimorphism of the scapula and the clavicle in a contemporary Greek population: applications in forensic identification. Forensic Sci Int 2012;217(1-3):231.e1-231.e7.

33. Jit I, Kaur H. Rhomboid fossa in the clavicles of North Indians. Am J Phys Anthropol 1986;70(01):97-103.

34. Hothorn T, Hornik K. Wiel MVd, Zeileis A. A Lego System for Conditional Inference. Am Stat 2006;60(03):257-263.

35. Hothorn T, Hornik K, Zeileis A. Unbiased Recursive Partitioning: A Conditional Inference Framework. J Comput Graph Stat 2006;15 (03):651-674.

36. Rogers NL, Flournoy LE, McCormick WF. The rhomboid fossa of the clavicle as a sex and age estimator. J Forensic Sci 2000;45(01): 61-67. 
Received: May 15, 2019

Accepted: October 18, 2019
Corresponding author

Renata Cristinny Campina

Email: renatacampina82@gmail.com 